\title{
Design for Deconstruction Using Integrated Lean Principles and BIM Approach
}

\author{
Mohamed Marzouk ${ }^{1, *(\mathbb{D})}$ and Ahmed Elmaraghy ${ }^{2}$ (D) \\ 1 Structural Engineering Department, Faculty of Engineering, Cairo University, Giza 12613, Egypt \\ 2 Integrated Engineering Design Management Program, Faculty of Engineering, Cairo University, Giza 12613, \\ Egypt; ahmedelmaraghy92@gmail.com \\ * Correspondence: mmarzouk@cu.edu.eg
}

Citation: Marzouk, M.; Elmaraghy, A. Design for Deconstruction Using Integrated Lean Principles and BIM Approach. Sustainability 2021, 13, 7856. https://doi.org/10.3390/ su13147856

Academic Editor: Steve

Kardinal Jusuf

Received: 4 June 2021

Accepted: 9 July 2021

Published: 14 July 2021

Publisher's Note: MDPI stays neutral with regard to jurisdictional claims in published maps and institutional affiliations.

Copyright: (c) 2021 by the authors. Licensee MDPI, Basel, Switzerland. This article is an open access article distributed under the terms and conditions of the Creative Commons Attribution (CC BY) license (https:// creativecommons.org/licenses/by/ $4.0 /)$.

\begin{abstract}
Existing buildings are characterized by the continuous change in the functional requirements of their end-users. As such, they are subjected to renovation or reconstruction, which is associated with total or partial demolition of the buildings, leading to an increase in construction and demolition waste. In addition, the materials abandoning the circular loop leave an adverse impact on the environment. This research integrates the building information modeling (BIM) approach and lean principles to ensure the early involvement of key participants in the decision-making process. This approach aids in planning the sequencing of deconstruction planning phases required before actual demolition activities take place. The paper presents the practical implementation of a BIM plug-in Tool. The assumptions and the scope based on which the plug-in was designed are briefly discussed. A case study for a mechanical, electrical, and plumbing (MEP) BIM model is introduced to illustrate the practical features of the proposed BIM plug-in Tool. The results encourage the selective dismantling of building elements based on the customers' needs. Building information modeling capabilities in deconstruction planning were also investigated. The proposed tool aids in decreasing the uncertainties involved in demolition projects. The tool can be implemented on a national level to automate the deconstruction projects and optimize the extraction of salvaged building elements. The recovery option for such elements and their final destiny can be secured with sufficient time before their dismantling from their original locations.
\end{abstract}

Keywords: building information modeling (BIM); design for deconstruction; lean principles; selective dismantling

\section{Introduction}

The construction industry is considered one of the major contributors worldwide of waste streams [1]. Construction and demolition waste (C\&D) represents 25 to $30 \%$ of all the waste generated in the EU [2]. Hosseini et al. [3] reported that the amount of salvaged materials being recovered and pumped back into the supply chain is considered less than the waste. This leads to a significant loss in materials and energy opposed by an increasing demand of virgin materials to meet the ever-increasing consumption rates [4]. The rising rate of demolition projects is caused by several reasons. Buildings are designed to last longer, however, the change in the users' functional needs are quite dynamic. This leads to a "use life cycle" of building materials that are shorter than their technical life cycle. In addition, conceiving our buildings as static, rigid structures with fixed connections hinders the possibility of the adaptability and reuse of building elements [5]. However, the recent years have witnessed a thorough investigation of barriers in adopting deconstruction planning processes that promote a circular loop supply chain in construction.

Time constraints are considered one of the main barriers in adopting less invasive deconstruction processes. Demolition contractors believe that deconstruction processes that focus on high material recovery is a time-consuming process with respect to mechanical 
demolition, which saves a lot of time [6]. Another complexity lies in the uncertainties related to the undocumented building conditions [7]. Most of the salvaged elements in a building are retrieved at the end of the building life cycle [3], where at that time, the building might lack a clear documentation of the modifications and changes applied throughout the operation and maintenance phase. Accordingly, precise evaluation of the current status of building elements remains a challenge. Not only do building conditions contribute to the uncertainties, but the logistics related to selling the salvaged elements are also a major source. This includes time, quantity, and location of the elements to be picked up and sent to the client for recovery or direct reuse [8]. In case these items still have an undefined destination, it will require a storage location whether on or off-site, which incurs more costs. Furthermore, in the case of on-site storage, it could affect the project schedule [9]. Therefore, deconstruction planning for the buildings should be executed with sufficient time before the actual demolition process starts. It should also be backed up by a clear understanding of the building conditions, detailed information about its elements and their recovery options, and the market needs for such elements. In this way, it is possible to optimize the deconstruction process to efficiently perform the dismantling of salvaged elements [10] with high recovery potential before the mechanical demolition activities take place.

This research augments the contributions made toward optimizing the deconstruction planning of buildings. The main objective of this research was to provide a procedure for deconstruction planning. The research also contributes to the establishment of a stable market for salvage elements and adopting a circular economic behavior in the construction sector. It is of outmost importance to find synergies between the energy and material savings when the salvaged elements are recovered, and the cost savings that can be achieved by selling these elements. The focus of this research is on the current stock of buildings. Although these buildings are reluctant to reap a high recovery value out of their elements, there is still a great possibility of extracting a portion of these elements with high recovery potential and pump them back into the supply chain. This could only be achieved if the building conditions are thoroughly investigated.

\section{Literature Review}

\subsection{Planning of the Deconstruction Processes}

At the end of the building life cycle comes what is known as the "demolition phase". Demolition is a linear process; it removes the building out of the supply chain loop. This is because demolition involves the elimination of all building elements at the end of the building life cycle and sending them to landfills [11]. This process produces gigantic amounts of debris, resulting in adverse environmental impacts [12]. On the other hand, deconstruction is emerging as an alternative to the demolition processes. Deconstruction is the systematic dismantling of buildings in order to maximize the recovery potential of building elements. The planning of the deconstruction process in a building is partly tied to what is called "reverse logistics". This term was identified as "the process of planning, implementing and controlling the efficient, effective inbound flow and storage of secondary goods and related information opposite to the traditional supply chain direction for the purpose of recovering value or proper disposal" [13].

Schultmann and Sunke [14] distinguished between recovery on the modules (an assembly of elements) or elements level and the recovery on the materials level. In a closed loop system, the smaller the loop, the less energy and material wastes are dissipated from the process. This means that recovery at the material level is regarded as the lowest recovery option as the element no longer exists in its original form, and it undergoes a "downcycling" process. However, the material is still in the supply chain loop, unlike the conventional disposal or incineration and being sent to landfills. Deconstruction is also described by the term "selective deconstruction" or "selective dismantling" [7]. This term was identified by Schultmann and Rentz [10]. The word "selective" points out the static nature of the current buildings, which makes it difficult to dismantle all the building elements available. 
Project planning, in general, constitutes two main components: strategic and operational. Accordingly, and in order to meet the required project goals, the deconstruction processes are planned both on the strategic and the operational level [7]. Strategic planning is more related to decision making on the macro level, while operational planning focuses on breaking down the work packages and planning the regular work on the tactical level. For instance, minimizing the overall project duration is considered a requirement for the strategic planning of a project. On the other hand, getting into the details of each activity in order to minimize its duration belongs to operational planning. Operational planning is considered "detailed scheduling", which is conceived from the strategic decisions made and the overall estimation of the general requirements. Therefore, the decisions made on the strategic level represent the reference that the operational goals and requirements are set up upon. Thomsen et al. [11] provided a detailed review of the deconstruction planning methods in the literature applied to both the operational and strategic levels. Since there is an obvious difference between the methods focused on strategic planning and others on operational planning, the research was classified based on the adopted planning method.

Several research efforts [15-17] have proposed a decision support system based on the analytic hierarchy process (AHP). The tool they developed helps in deciding between the different demolition techniques based on economic, environmental, technical, and social criteria. The three strategies to choose from include progressive demolition, which is the controlled removal of sections of the structure; deconstruction or dismantling a structure, which is usually carried out in reverse order of construction; and finally, the deliberate collapse mechanism or what is known as mechanical demolition. The latter strategies are then assessed quantitively against the overall costs, where selling salvaged elements recovered in both the first and second strategies are deducted from the costs incurred. Moreover, Anumba et al. [18] continued toward an explanation of different demolition techniques for the contractor to choose from. This was followed a presentation of the criteria needed for the selection of the optimum demolition technique. These criteria included time constraints, financial constraints, environmental considerations, and recycling considerations. However, the results were not formulated into a decision-making model. Instead, the author provided guidelines on selecting the most convenient strategy based on the mentioned criteria.

Liu et al. [19] proposed a detailed cost analysis to evaluate the economic performance of different strategies. Based on actual case studies, the authors concluded that deconstruction was the best strategy to be adopted for the cost savings it guarantees. Kourmpanis et al. [20] introduced a multi-criteria decision-making model (PROMETHEE II) to investigate the different waste management strategies at the end of the building life cycle. The research was more focused on the material recovery options rather than focusing on the reuse potential of the building components. The proposed material management system relied on several criteria. These criteria were classified under four groups: social-legislative, environmental, economic, and technical. Schultmann and Sunke [21] extended their work to include the amounts of energy savings due to different construction strategies. Moreover, Volk et al. [22] managed to link the strategic and operational planning by developing a decision-making system that plans the organization resources to solve multi-project scheduling problems. Afterward, Sunke [23] introduced different optimization models for deconstruction planning, however, it should be noted that these models did not consider uncertainties in their objective functions.

\subsection{Use of Digital Technologies in Deconstruction Projects}

BIM is revolutionizing the architecture, engineering and construction (AEC) industry. BIM is defined as the [24] "digital representation of physical and functional characteristics of a facility". It is the process of producing and maintaining project related information throughout the different phases of the building life cycle $[25,26]$. The information not only constitutes geometric properties of the building elements, but also extends to include any customized information related to the building. There are various uses for BIMs, 
which include 3D visualization, 4D scheduling, quantity take-off, etc. Although the use of BIM functionalities is an active field of research, exploiting the advantages of BIM in the deconstruction stage remains limited [27]. The development of BIM-based tools exploiting the domain of waste minimization in the construction industry can be classified into three groups. The first focuses on assessing the de-constructability of buildings or to what extent they are designed for disassembly (DFD) and circular economy [28,29]. The second focuses on construction waste minimization [30], while the third is concerned with the waste associated with the demolition or renovation of buildings and evaluating different deconstruction options [31-33].

The work of Akbarnezhad et al. [31] involved the development of a BIM-based plugin to assess different deconstruction strategies. The operational flow of processes relied on customized deconstruction-related attributes. These attributes are then attached to its corresponding BIM object. Then, the proposed tool analyzes the data entered and depicts the suitable overall deconstruction strategy that achieves the optimum solution in terms of costs, energy use, and carbon footprint. This BIM-based framework included the environmental aspects in the decision-making criteria. These aspects were not only related to on-site activities, but also extended to include the transportation logistics. For instance, the carbon emissions caused by the transportation trucks hauling the salvaged materials to the recycling or disposal facilities were included in the assessment criteria. It is worth noting that recycling facilities process different varieties of construction materials [34-36].

\subsection{Using BIM within Lean Construction Principles}

Many research efforts have highlighted the importance of synergies between BIM and lean concepts [37-41]. The exploitation of both BIM and lean relies on the proper understanding of their theoretical processes. This integration is expected to yield more benefits to the construction industry than just the implementation of each one of them independently [37]. Since BIM and lean principles can be adopted separately, there is a need to prove that the integration should yield better results. Several initiatives have been dedicated to this approach, an example of which is integrated project delivery (IPD), and another is virtual design and construction (VDC). As for IPD, it mandates the project participants be involved in decision making as early as possible in the project. Additionally, IPD forms of contracts are designed for "collaborative project delivery". In other words, it is a framework within which the owner, designers, and contractors are required to work together. In other words, there is no more room for the individual gains in the project by one entity, instead, the revenue gained by all project participants is tied by the project success [42]. Accordingly, new forms of contracts have been introduced to the construction market based on the IPD approach, an example of which are those forms of contracts issued by the American Institute of Architects (AIA). One of these forms is the AIA Document E202-2008. This document provides a framework for the adoption of BIM in IPD projects. This comprehensive framework based on BIM protocols, the level of development, and model elements is proof that BIM can yield extra benefits when applied in a collaborative environment [43]. Finally, IPD is an approach that adopts lean principles and encourages the use of BIM tools and processes.

Furthermore, when it comes to the term virtual design and construction (VDC), it has been defined by the Center for Integrated Facility Engineering (CIFE) at Stanford University. VDC is involved in the alignment of the BIM process with lean construction practices [44]. The term is sometimes interchanged with BIM in a lean context. Gilligan and Kunz [45] reported that using VDC in the early project phases facilitated the implementation of lean construction methods. The early involvement of key participants, along with the application of lean delivery process, has been leveraged by the 3D data rich models. The result of true value engineering had saved $\$ 6 \mathrm{M}$ in the project driven by owner Sutter Health in California. From IPD and VDC, it is clear that the initiatives for collaborative work and lean thinking implementation are stressing the significance of BIM processes. In order to capture the interaction between lean principles and BIM functionalities, Sacks et al. [37] 
provided a framework for analyzing these interactions. They arranged them in a matrix, where each BIM functionality is analyzed against each lean principle. The result can be positive, which indicates full compliance to the indicated lean principle, or negative, where the BIM functionality opposes the lean principle in its implementation. After postulating the interactions, Sacks et al. [37] sought evidence to support each of them. Evidence was either theoretically proposed in previous research efforts or has been retrieved from practice. In some cases, the interaction was inferred from the informed reasoning of the authors. Thus, they suggested that more investigation is needed to prove the reliability of their suggestions. Their results showed a near complete synergy between BIM functionalities and lean principles in construction projects. The framework is regarded as being suitable for exploratory research where the conformity between two processes that are needed is identified and explored, especially when one is in the form of general principles and the other provides practical solutions and functionalities that are aligned with the core concepts of the principles. This constructive approach was then extended and built upon by other researchers.

For instance, Oskouie et al. [46] built on the interaction matrix of Sacks et al. [37]. The new matrix was extended with additional lean principles and BIM functionalities. The authors classified the principles into main categories rather than breaking down the categories. The reason was that some of the sub-categories provided by the Sacks et al. [37] matrix was related to the production process, whereas the extended framework dealt with BIM functionalities that support the operation and maintenance phase or the "facility management". In this phase, BIM functionalities are more involved with the general lean concepts apart from the production process. The authors reached the conclusion that BIM-enabled tools, when used in the operation and maintenance phase, guarantees the "lean" execution of the process. Consequently, the costs related to maintaining the facility can be reduced.

The use of BIM technologies that lineate with lean principles has been investigated in the construction projects. However, the analysis of synergies between BIM and lean in deconstruction processes is only merely mentioned. Most of the research efforts that exploit the BIM-lean integration in reducing the amounts of construction and demolition wastes (C\&D) have focused on wastes generated during the construction phase. For instance, Cheng et al. [47] investigated the use of BIM functionalities in enabling the waste minimization in construction processes. Among these functionalities were design validation, quantity take-off, phase planning, and site utilization planning. Therefore, the perspective of optimizing demolition and deconstruction processes have not yet been explored within a lean-BIM interaction perspective.

\subsection{Limitation and Research Gaps in Deconstruction Planning}

Based on the comprehensive literature review, some of the current research gaps and opportunities in leveraging deconstruction planning are provided. To start with, detailed project planning techniques need to be further developed, and the use of BIM-based scheduling capabilities can be a handy solution. This option was implicitly suggested by Hübner et al. [7] by stating that the improvements in computer applications will enable the planning of activities with a high level of detail. This can be done by adapting the IT-based computational solutions for the planning of construction activities to be used for deconstruction planning. Furthermore, Hübner et al. [7] found that the current deconstruction planning problems on the operational level are optimized using single-objective functions or a single-criteria is involved. Multi-criteria decision making was only applied on the strategic level. Therefore, several criteria affecting the deconstruction planning should be taken into consideration. This would increase the accurate simulation of the solutions to real-world problems that are expected to happen. The use of BIM simulation capabilities could also be a suitable environment for evaluating different scenarios. Furthermore, several criteria affecting the deconstruction planning have never been mentioned in previous research. One of these remains the customer satisfaction, a cornerstone in establishing 
a successful business. Customer satisfaction in deconstruction is partly involved with the quality of the salvaged elements to be dismantled, since the customer is mainly the buyer of these salvaged elements. These customer segments extend from recycling facilities that deal with buildings on a material level to include new construction projects that directly reuse the salvaged elements. When considering the overall project quality, the environmental impact should be taken into consideration. Akinade et al. [48] mentioned some criteria related to the environmental impact of transporting the salvaged elements, however, the impacts of using different deconstruction tools and techniques have never been mentioned in a quantitative analysis nor the compliance to environmental standards. Additionally, there are no sensors currently used in the context of tracking the impacts resulting from deconstruction activities. Perhaps a reason would be the extra costs incurred to buy these sensors and the lack of regulations that necessitates the application of this kind of environmental assessment.

Additionally, capturing the current state of buildings was fairly mentioned in Ge et al. [49]. The modifications and repair of building elements necessitate the documentation of the latest conditions before deconstruction. This is considered as one of the major uncertainties in deconstruction planning, however, these uncertainties are often not taken into consideration in the decision making. Furthermore, on the strategic level, current integrated project delivery methods require the early involvement of key participants in the project, which would back up the early informed decision making. However, this approach has not been considered in deconstruction planning yet. This approach would also be beneficial for creating long-term relationships and building up an extended network of partners.

\section{Proposed BIM-Lean Interaction Matrix}

In accordance with the BIM-lean interaction matrix developed by Sacks et al. [37], the aim of this research was to extend the use of this interaction matrix to explore the possible potential of implementing lean concepts through BIM-related functionalities in deconstruction projects (see Table 1). First, the need to detect the conformity of lean principles and BIM functionalities is explored. Afterward, the feedback of the resulting interactions can lead to a decision on whether to adopt these principles and functionalities. This can be regarded as laying a foundation for a more structured demolition practice [50,51]. It should be noted that the impact of each BIM-functionality on each lean principle was postulated based on the definitions of each functionality and principle. In the matrix, each cell links a certain BIM functionality with a lean principle. If it contains a number, then this indicates that there is a possible interaction between them. It is worth noting that positive numbers indicate a positive interaction, while numbers in between brackets indicate a negative interaction. 
Table 1. Interaction matrix of lean principles and BIM functionalities.

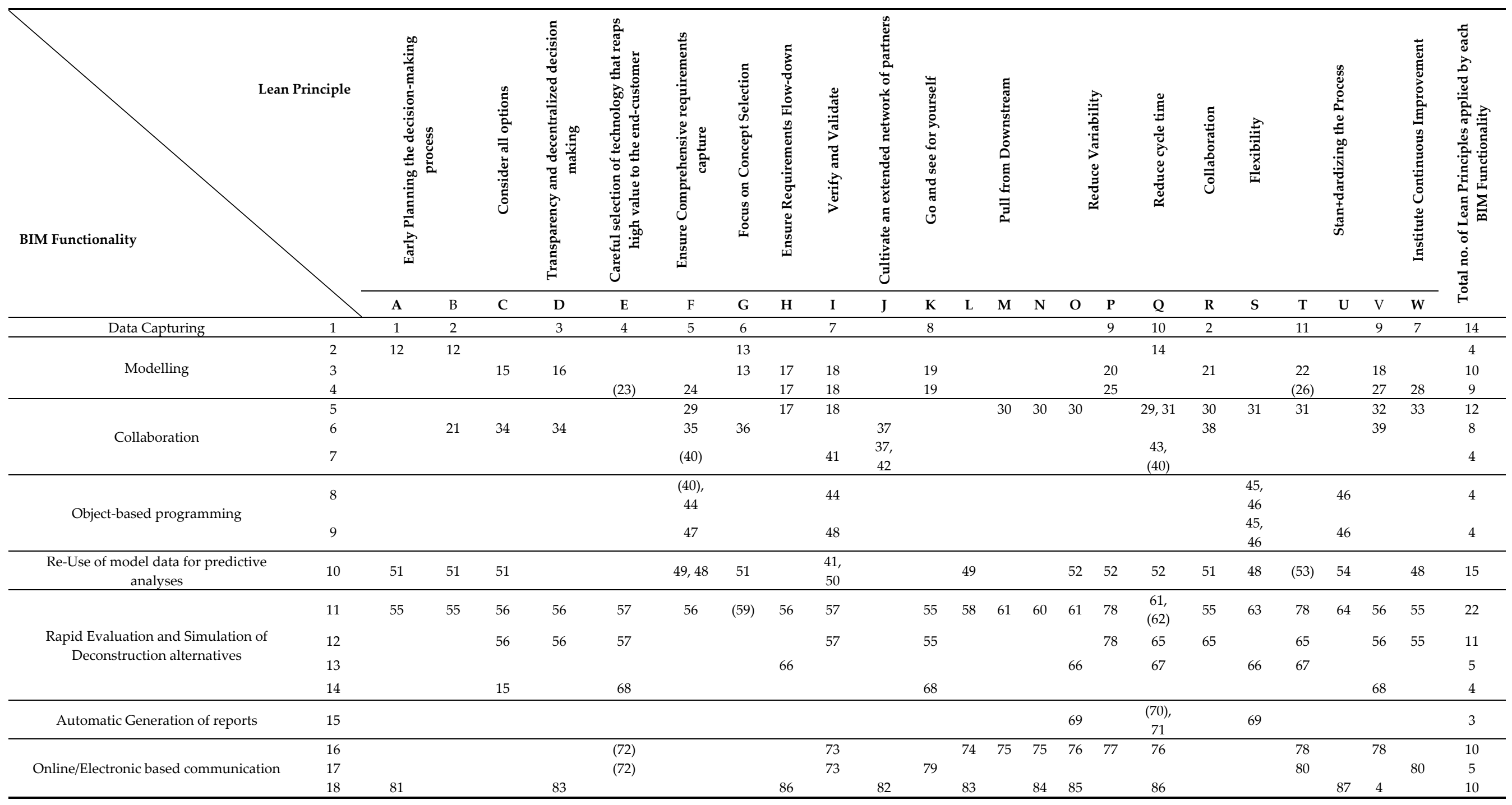


Table 2 provides the explanation for a sample of interaction indices that are listed in Table 1. For each explanation given in Table 2, the evidence, based on which the interaction was inferred, is mentioned. There are four main types of evidence:

- Type 1: A previously identified evidence in the construction context or in general. Proof of evidence of its applicability in deconstruction processes might be needed.

- Type 2: A source of evidence recorded in deconstruction context. It was retrieved from the literature and its outcome is documented by the relevant authors.

- Type 3: Evidence captured from practice in actual deconstruction or demolition projects. The explanation is deemed to be proven by such empirical evidence.

- Type 4: They are areas where no evidence has been detected yet. They are regarded as an expected projection of integrating processes from the literature and practice to enhance the throughput results. Therefore, their source of evidence is deemed "not yet available".

Table 2. Explanations of each interaction in the matrix and providing its evidence from research or practice.

\begin{tabular}{|c|c|c|}
\hline Index & Explanation & Evidence Type \\
\hline 1 & $\begin{array}{l}\text { The scanning process which captures the building data, is a quick and efficient process. Once it is } \\
\text { collected quickly on-site, the decisions on the building deconstruction can be planned sufficient } \\
\text { time before actual demolition activities take place. }\end{array}$ & 2,3 \\
\hline 2 & $\begin{array}{l}\text { Organized meetings with the persons who can do the work, early in the process, is enhanced by } \\
\text { visualizing the site-data in the office. This gives a chance to discuss the decisions based on the } \\
\text { actual conditions and with the people involved in the actual dismantling processes. }\end{array}$ & 1 \\
\hline 3 & $\begin{array}{l}\text { Visualization of the actual building conditions through digital documentation is a transparent } \\
\text { process. Instead of written reports, witnessing the current building conditions contribute to a } \\
\text { transparent decision-making process. }\end{array}$ & 3 \\
\hline$\cdots$ & $\cdots$ & $\cdots$ \\
\hline$\cdots$ & $\cdots$ & $\cdots$ \\
\hline 86 & $\begin{array}{l}\text { Removal of order processing steps (by linking BIM database and synchronizing it with the } \\
\text { updates on the sold salvaged elements on the online store) improves the cycle time (time needed } \\
\text { for elements to be dismantled and delivered). }\end{array}$ & 4 \\
\hline 87 & $\begin{array}{l}\text { By carrying out the deconstruction processes based on the information on the sold salvaged } \\
\text { elements retrieved from the online store, dismantling (standard) activities can be recognized. } \\
\text { Similarly, the dismantling of the rest of elements with unknown second destination can be } \\
\text { postponed till a demand arises for them. This process can provide a structure for executing the } \\
\text { work that takes uncertainty into consideration. }\end{array}$ & 4 \\
\hline
\end{tabular}

The outcome of interactions in the matrix revealed interesting results when it comes to understanding the relationships between various BIM functionalities and lean principles. This would give insights on how to plan for deconstruction projects. The interactions also require in-depth understanding to validate their applicability in practice. There were hundred and fifty-four (154) interactions, of which eighty-seven (87) were unique. Seventyeight (78) of the eighty-seven (87) unique interactions indicated a positive impact, while the remaining nine interactions indicated a negative impact or a contradiction to the lean principle investigated.

To start with, the lean principles with highest concentration of interactions were: "verify and validate", "reduce cycle time", and "standardizing the process through finding simplicity even within complex projects". The first is a core lean principle that ensures the continuous verification and validation of the project throughout the production process. By applying this principle, it is possible to control the deconstruction process and ensure that the dismantled salvaged elements meet the end-customers' requirements. In addition, the elements' conditions are verified for their recovery potential. 
Second, since "reduce cycle time" is among the top lean principles with the highest interactions with BIM functionalities, this means that BIM-based processes effectively reduce the overall cycle times of different activities. This proves that the time exhausted early in the process to capture the building details and data is finally rewarding. The informed decisions, along with visualization and simulation of different processes, ensures that less time is spent on actual dismantling activities. Similarly, "simplicity" is also achieved in the execution of dismantling activities through the thorough planning of deconstruction projects using BIM processes, despite some complexity in the integration of discrete data sources within the BIM model and other discrepancies in detecting patterns between different BIM objects.

Furthermore, BIM functionalities that appeared to have the highest number of interactions with lean principles were: "deconstruction processes simulation 4D scheduling", "reuse of model data for predictive analysis", and "the digital documentation from remote sensing data". This output makes sense to a great extent. Starting in chronological order, data capture through digital documentation is regarded a unique process when it comes to deconstruction projects. It is the starting milestone based on which the rest of the data layers are accumulated. Second, the wide range of analysis provided by external plug-ins serve a large span of lean principles. It also adds an edge to the BIM model by adding intelligent layers of analyzed data. Finally, the 4D scheduling and deconstruction process simulation had the highest number of interactions. Besides being the significant reason for adopting BIM processes in traditional construction projects, the simulation capabilities of BIM can be extended and exploited in the deconstruction process.

On the other hand, the principles that appeared to be served the least or were even negatively impacted were "cultivate an extended network of partners" and "remove variations in workloads to create a smooth flow". Having fewer interactions does not necessarily mean that they are neglected. Perhaps these principles are not explicitly served by BIM processes, while the BIM functionality with less interactions was the "automatic generation of reports". It also has a negative impact on the "cycle time". Reasons for that were mentioned in the explanation table, where the ease of the generation of reports yields an undesired amount of data. This could cause more wasted time on determining and tracing the latest working version of data.

\section{BIM Plug-In Tool}

\subsection{Plug-In Designated Functions}

After inserting all building data into the BIM model, the BIM plug-in analyzes and prioritizes the salvaged elements based on their recovery potential. The BIM model should also be linked to a "web-shop" for showcasing the salvaged elements. The elements with high recovery potential are then uploaded directly to the web shop. This shop could have a mobile compatible version for ease of access. Based on the demand of the salvaged elements by customers, the required elements are then updated on the BIM model. These elements are then ready to be scheduled for deconstruction. The third output of the plugin is its automatic execution of the dismantling sequencing and the deconstruction $4 \mathrm{D}$ schedule. This is done based on the elements sold on the web-shop. It is to be noted that elements should be uploaded on the web shop with sufficient time before actual demolition activities take place in order to allow time for dismantling these elements.

Once the execution starts, the salvaged elements are to be extracted from the deconstruction site based on the designated schedule. Any update from the web-shop is instantly updated on the model and the schedule accordingly. This would allow for a robust optimized process. In addition, the plug-in also provides a detailed element dismantling map for the model. This map helps in visualizing the different constraints surrounding the extraction of certain building elements along with the interdependencies between various building elements. Finally, the salvaged elements dismantled are transported to their new clients. Any elements remaining in the building then undergo traditional demolition 
processes. Most of the remaining materials are recycled. Therefore, the BIM plug-in adopts the selective dismantling concept mentioned before.

\subsection{Plug-In Implementation}

The aim of developing this plug-in tool, in the first place, was to capture the implicit patterns of connectivity and relationships between various BIM objects. Detecting and visualizing these relationships can support an informed decision on the deconstructability of different elements, the effect of dismantling a certain element on its surrounding, and the interdependencies between various building elements. Consequently, this application relies on BIM capabilities in supporting the deconstruction processes and exposes some of the discrepancies that may hinder full exploitation of these capabilities. The plug-in tool was developed using the programming language C\#, since Autodesk Revit ${ }^{\circledR}$ API supports the .NET Framework. The API provides access to Revit documents, applications, and the database. It also comprises a large set of supplementary classes, apart from the classes representing the building elements. These sets are considered of great utilization for further development in the Revit environment. Examples of these classes are: elements collection filters, Boolean filters, geometry creation utilities, geometric operations, etc.

The first trials for the plug-in were developed using Dynamo, which is an open source, visual programming tool. It was mainly developed for Revit ${ }^{\circledR}$ to promote computational design [52]. The dynamo environment is a perfect hub for prototypes with limited amounts of data to iterate over because the visual programming interface is not yet quite handy when it comes to providing all functions in any programming language. In addition, since dynamo allows scripting in Python [53], it is important to align it with the nodes and wires of Dynamo's interface. Consequently, the decision was to go for a .NET plug-in since Revit ${ }^{\circledR}$ supports a .NET application. The plug-in tool objectives include the automatic detection and mapping of:

- Building elements relationships with respect to host elements;

- Physical connectivity of MEP elements and the interdependent relationships in each system;

- Structural dependencies according to the building structural system; and

- Elements affected by the dismantling of a certain embedded MEP element.

This application captures the relationships between building elements and detects them within the BIM objects in a model. Hence, the scope of the application covers any BIM model designed based on the traditional construction concepts. This can include as-built models of historic buildings or BIM models of future buildings. However, when the design-for-disassembly concepts are realized in the form of new building elements with high transformation capacity, new rules should be added to the application to account for these changes (see Figure 1).

The scope of infrastructures like tunnels, bridges, and roads was not included in the application as well as any industrial facility. However, domestic and office buildings can be evaluated using this plug-in. In addition, schools, hospitals, and other service buildings can be assessed, however, the categories of elements specific for each building type should be added to the plug-in categorized list of elements before evaluation. This ensures the reliability of results and the comprehensive analysis of all building elements. Since MEP systems account for around $40-60 \%$ of the total construction cost [54], the thorough investigation of their interrelations and dependencies is regarded as a crucial step in the end-of-life assessment of the building elements and their recovery potential. Therefore, accurate information on the connectivity of MEP elements, their dismantling sequence, and their interference with other building parts are given a great importance in this study. 


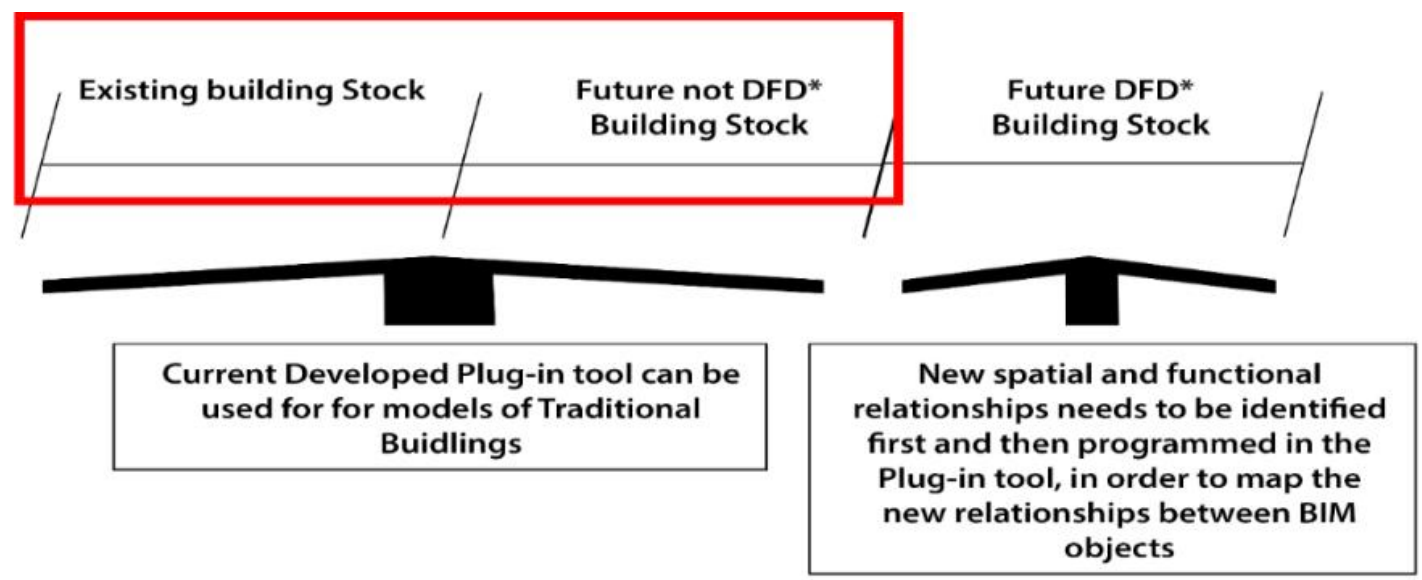

*DFD : Designed for Disassembly

Figure 1. Process map of the proposed BIM plug-in.

\section{Case Study}

\subsection{Case Description}

The building consists of around 5400 MEP elements. It is a 3-storey-office building provided by Autodesk Revit ${ }^{\circledR}$ [55] as a sample for an advanced MEP model (see Figure 2). The model exposes various types of MEP systems' installations including different types of ducts, air terminals, lighting devices and fixtures, cable trays and associated wirings, electrical fixtures, firefighting systems (sprinklers), sanitary and plumbing fixtures and its related piping systems, and different mechanical and electrical equipment. Figure 2 shows the main building as well as cross sections from different floors. The building contains false ceilings in some areas. In these areas, the mechanical ducts run above the ceiling, while in other areas, the ducts and the related terminals and diffusers appear directly hanging below the subsequent floor. Different installation scenarios affect the deconstruction sequencing for different MEP objects.
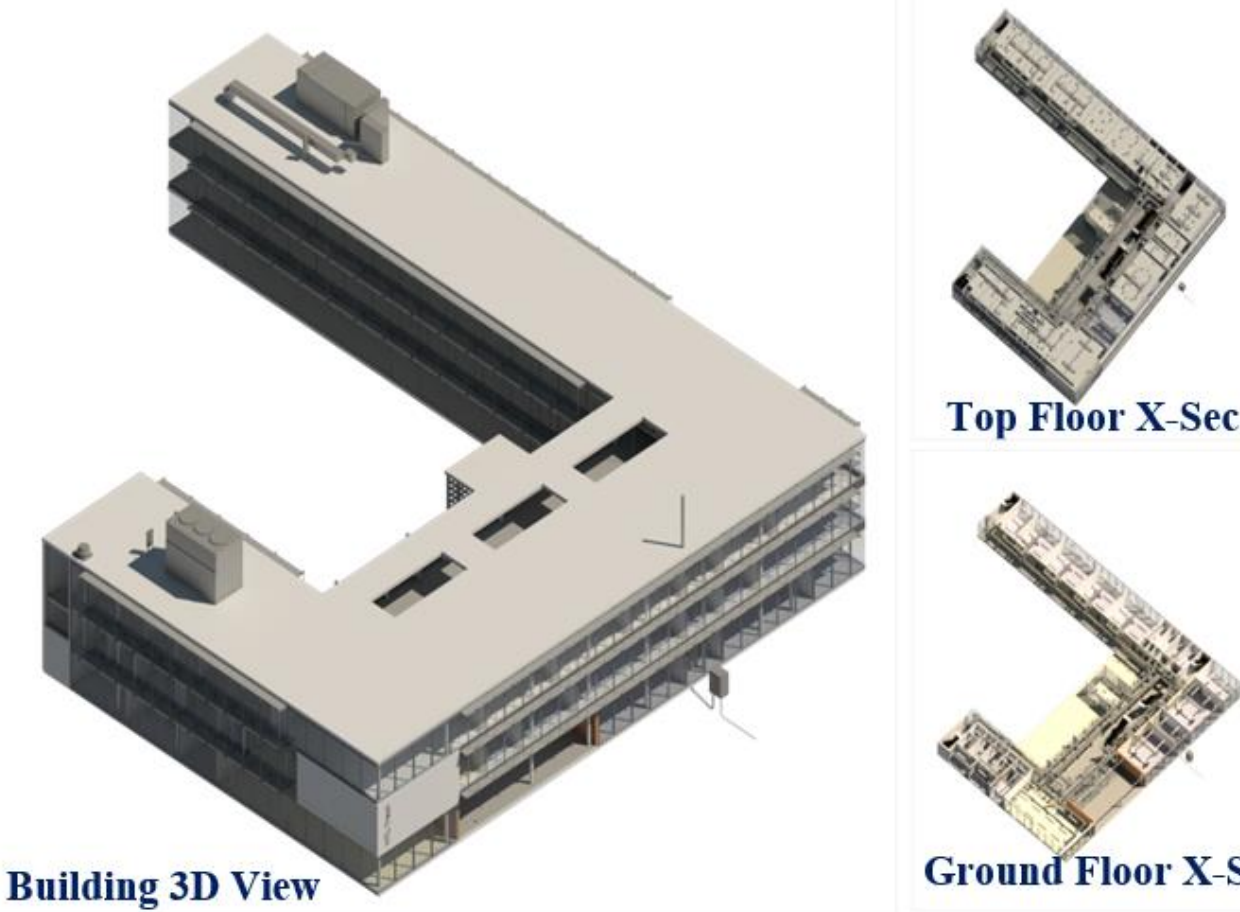

Top Floor X-Sec.

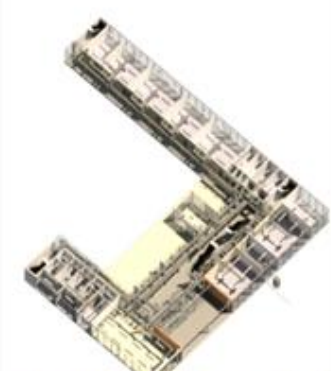

Ground Floor X-Sec.

Figure 2. Case study the 3-storey office building. 
A more detailed listing of different MEP categories and the amount of contribution of these systems to the total MEP elements is presented in Figure 3. A thorough analysis of MEP systems is crucial in order to assess the deconstructability of their different elements. This was the main reason for choosing the model provided by Autodesk Revit ${ }^{\circledR}$. Besides the need to investigate the different relationships between MEP objects and its surrounding structural elements, relying on a complete model that integrates all construction disciplines was a necessity. However, several challenges and errors were detected in the model. This requires taking the necessary precautions to avoid facing these problems, especially when trying to exploit the BIM model in deconstruction sequencing and analysis of the elements' dismantling processes.

Ducts and Terminals

Lighting fixtures and Devices

Electrical Fixtures and Wiring

Fire Fighting

Pipes

Equipment

Cable Trays

Sanitary

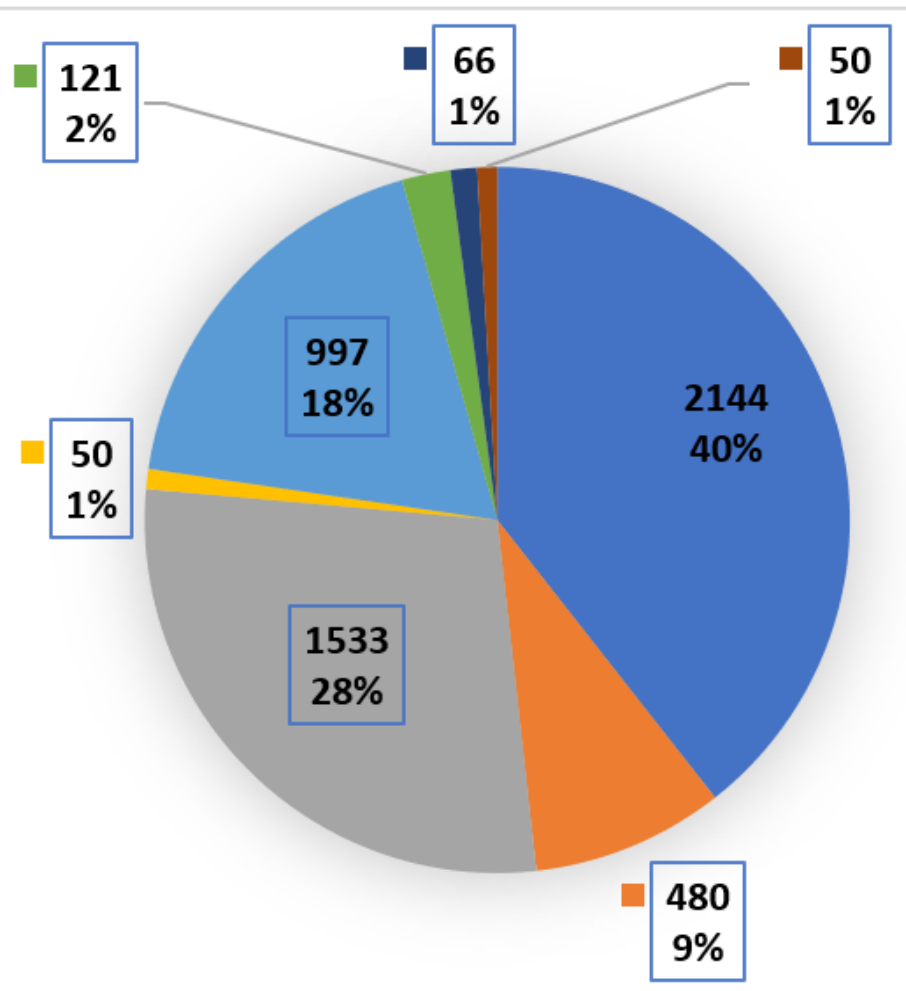

Figure 3. Classification of the MEP elements in the case study BIM model.

\subsection{Building Elements Relationships with Respect to Host Elements}

Taking the building level as a starting point, the components in each level are filtered to retrieve the host elements like walls, floors, and ceilings. Host elements are considered the core layer for the building that has the least transformation and deconstructability potential. On the other hand, elements with high turnover rate are mainly the services layer. This includes the MEP fittings, connectors, and relevant equipment. In addition, doors and windows remain among the elements with high reuse potential depending on their design style and the how their components are connected and assembled. That is why detecting the interdependencies and physical relationships between both elements is crucial. This helps in assessing the possibility of extracting the elements with high reuse potential while preserving its quality. Therefore, this functionality provides a detailed mapping procedure that studies how each MEP object interacts with the host elements. The analysis on walls is done separately while floors and ceiling are studied together. The analysis of elements for their relationships with wall elements are divided into three categories:

\subsubsection{Category 1: MEP Service Connections}

These are MEP connectors such as ducts, flex ducts, pipes, conduit, and cable trays. These elements have three scenarios in their relationship with walls. First, a MEP service 
connector can be embedded in the wall. For example, heating pipes can be embedded in the wall. The second scenario is that a floor serving connector can be passed through the wall like a mechanical duct that is connected to a diffuser inside a room and passes through its wall. The third scenario is that an MEP element ends just at the end of the wall. The most common case is a duct ending with an air terminal at the face of a wall (see Figure 4). As shown in Figure 4, floor service connectors, mostly passing through wall objects or ending at the walls, are detected and highlighted in blue after the analysis.

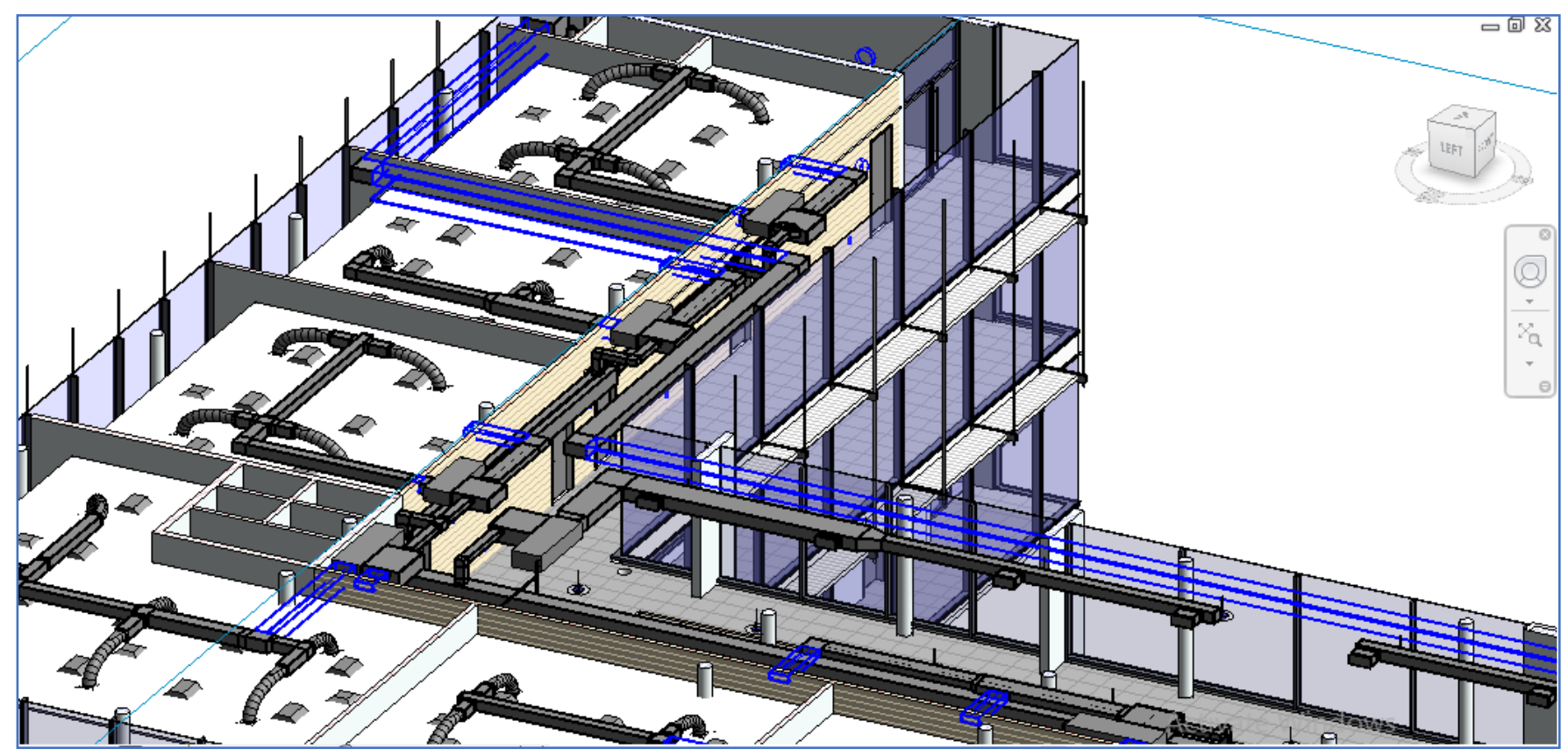

Figure 4. Floor service connectors.

\subsubsection{Category 2: Face-Based MEP Elements}

These are MEP fixtures and equipment such as air terminals, lighting fixtures and devices, electrical fixtures and equipment, and mechanical equipment. These elements have only two scenarios in their relationship with walls. Since they are attached to the face of the wall, they are either attached to the exterior side or the interior side of the wall. In this context, exterior and interior terms are used to denote both sides of the wall regardless of whether its functionality is for the exterior façade or is located inside a building. These elements are characterized in Revit ${ }^{\circledR}$ by having a point if inserted in the model, thus it has a location point and not a location curve like ducts and pipes (see Figure 5). As shown in Figure 5, MEP elements, mostly lighting fixtures and sensors that are attached to wall elements, are detected and highlighted in blue after the analysis.

\subsubsection{Category 3: Doors and Windows}

In addition to the normal doors and windows, there are some specialty equipment like the elevator automatic doors. These elements are installed within a wall. Detecting the doors and windows installed in each wall helps in the quick identification of their location. The walls might be prefabricated and can be used as is with the doors or windows inserted in them (see Figure 6). As shown in Figure 6, doors and windows attached to wall elements are detected and highlighted in blue after the analysis. 


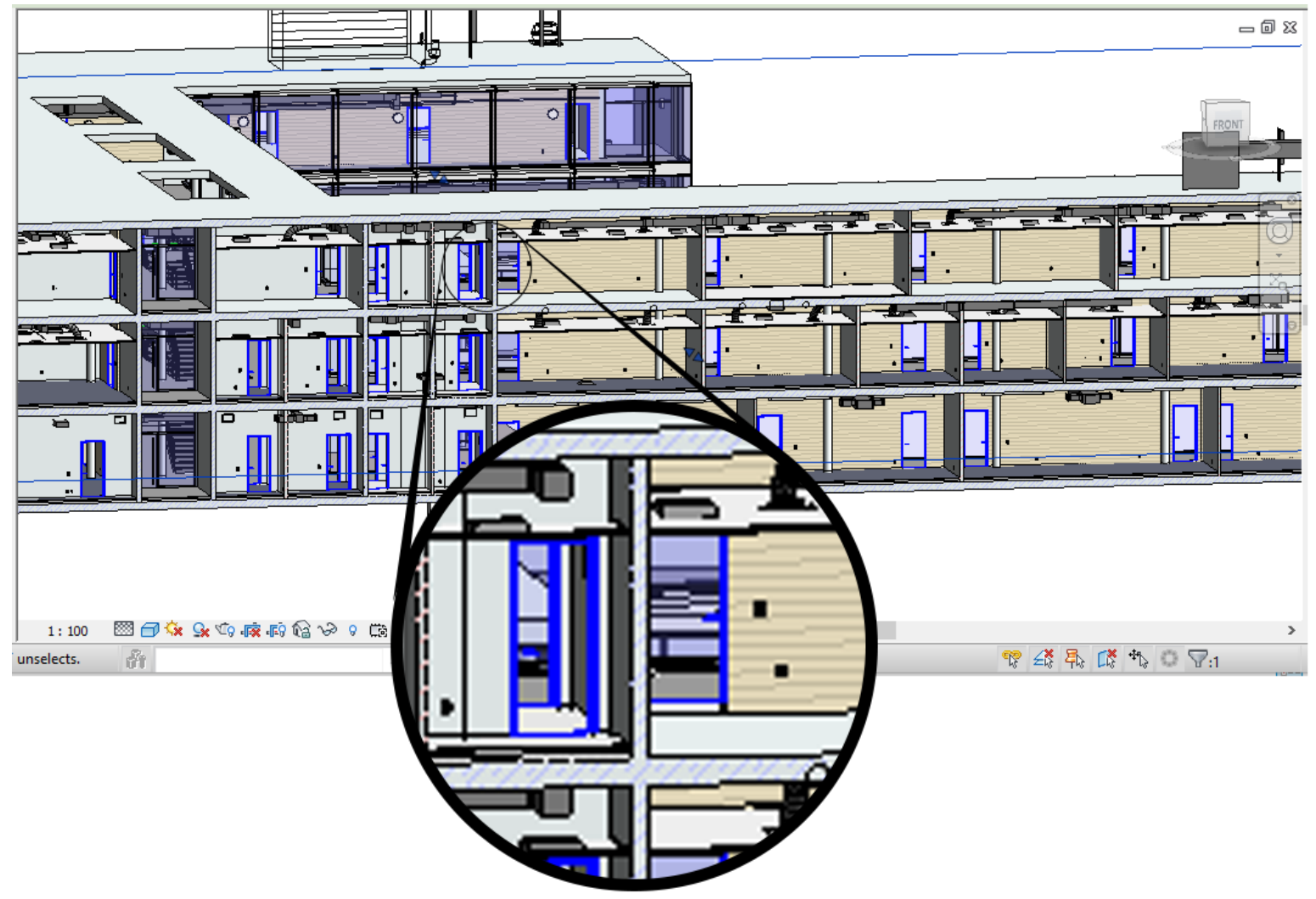

Figure 5. Face-based MEP elements in relation to wall elements.

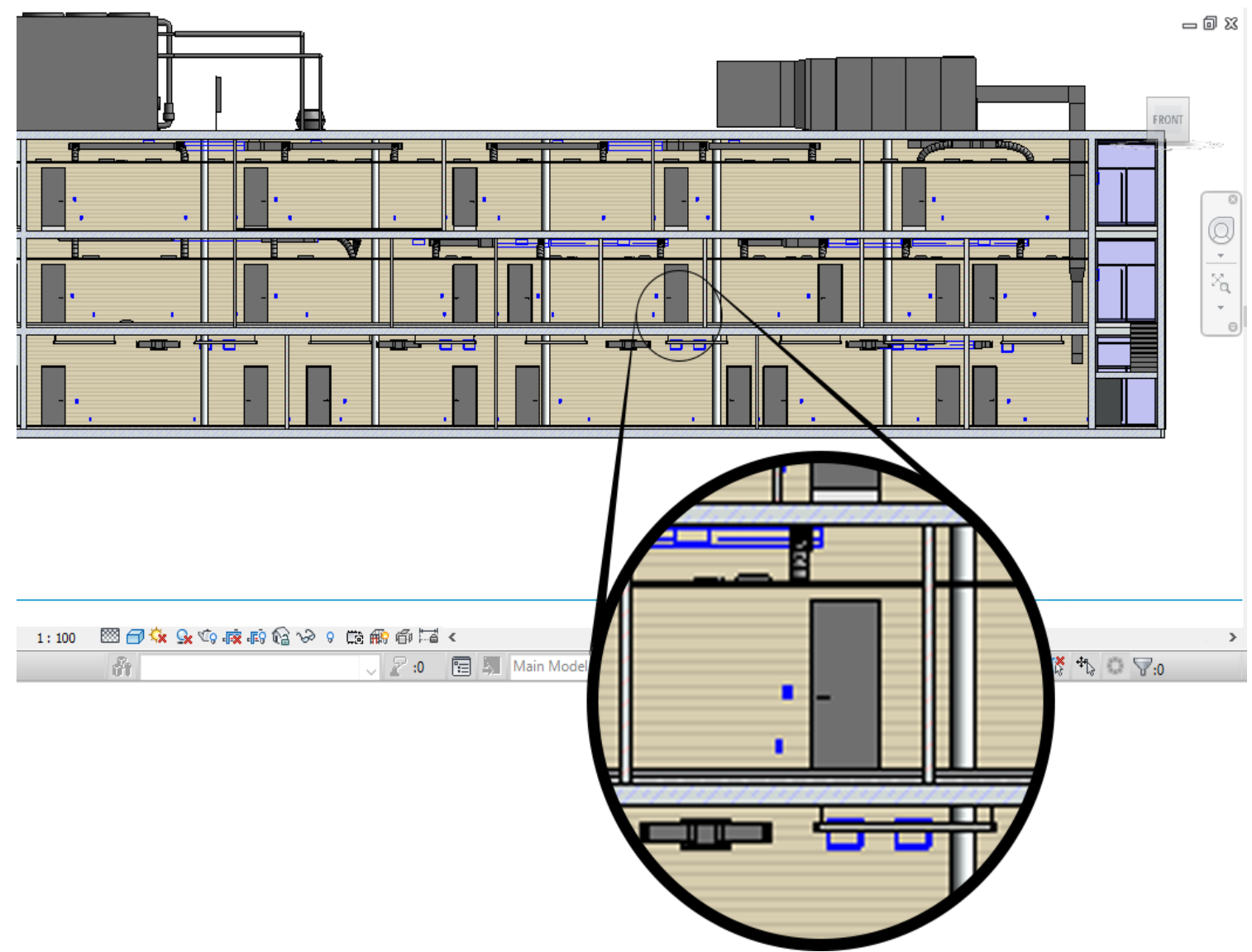

Figure 6. Doors and windows in relation to wall elements. 


\subsection{Running BIM Plug-In Tool}

In analyzing floors and ceilings, the zones and spaces relevant to the MEP systems are the components to be considered. Each building zone is studied for the availability of ceilings. If so, there are three scenarios for MEP elements.

- 1st Scenario: MEP element is hiding or installed behind the "false" ceiling such as ducts, flex ducts, pipes and cable trays.

- 2nd Scenario: MEP elements are embedded in the ceiling. These items are probably lighting fixtures that are in place of some ceiling tiles.

- 3rd Scenario: MEP elements are hanging from the ceiling. These items vary from lighting fixtures attached to the ceiling to firefighting related units like sprinklers.

In the case no ceilings are found within a certain space, there are three scenarios related to the MEP elements and their hosting floor. The second and third scenarios examine the elements running below the floor, which is considered as the ceiling in the level below it.

- 1st Scenario: MEP elements are embedded in the floor. An example could be the drainage pipes that are embedded during construction of the building into the floor.

- 2nd Scenario: MEP elements are hanged down from the floor. Same as in the ceilings, but in this case, the lighting fixture is hanged to the bottom side of the structural floor.

- 3rd Scenario: MEP service connectors are passing under the floor. These are elements like ducts and cable trays. This occurs in some office buildings where they find the MEP systems uncovered and hanged directly to the bottom of the slab.

The algorithm iterates over the MEP elements of category 1 "MEP service connections" and category 2 "MEP face-based elements" simultaneously. First, two "element filtered collectors" are set: one for the MEP service connectors like ducts and pipes, and the other for the MEP face-based elements like lighting fixtures and duct terminals. These filtered collectors capture all the MEP elements in the BIM model that meet the categories mentioned. Then, another filtered collector is used to select all the walls in the project. After making sure that the wall is not a type of curtain wall, the analysis for the "category 1" elements is initiated. The solid geometry of the wall is retrieved. This ensures that the whole geometry of the original wall is captured, where no openings or any voids are present. This solid geometry is used as an intersection filter to detect if any of the category 1 elements intersect with this solid body. Once the list of intersected MEP elements is extracted, the iteration is performed over each MEP element to analyze the type of intersection with the wall (embedded, ending, or passing). The resulting data in each iteration are then exported to MS Excel in the same manner as discussed in category 1 elements as listed in Table 3. These lists altogether represent the "nodes" of the network. The output is then visualized on the model itself. Element of categories 1 and 2 that had interactions with the building walls are highlighted and are visualized in Figure 7.

Table 3. Exported nodes and edges.

\begin{tabular}{cccccc}
\hline & Nodes & & & \multicolumn{2}{c}{ Edges } \\
\hline ID & Element Type & Element Category & Wall ID & MEP Element ID & Label \\
\hline 573298 & STB 30.0 Rot & Walls & 573298 & 451046 & Face-based Interior \\
\hline 573299 & STB 30.0 Rot & Walls & 573299 & 466527 & Face-based Exterior \\
\hline 573316 & STB 30.0 Rot & Walls & 573317 & 411084 & Passing \\
\hline 451046 & Passive Infrared-277 V & Lighting Devices & 573381 & 427618 & Ending \\
\hline 466209 & Standard Elec & Electrical Fixtures & 573575 & 414122 & Embedded \\
\hline 711765 & Standard Pipes & Pipe Curves & & & \\
\hline 626004 & LP-3B & Electrical Equipment & & &
\end{tabular}




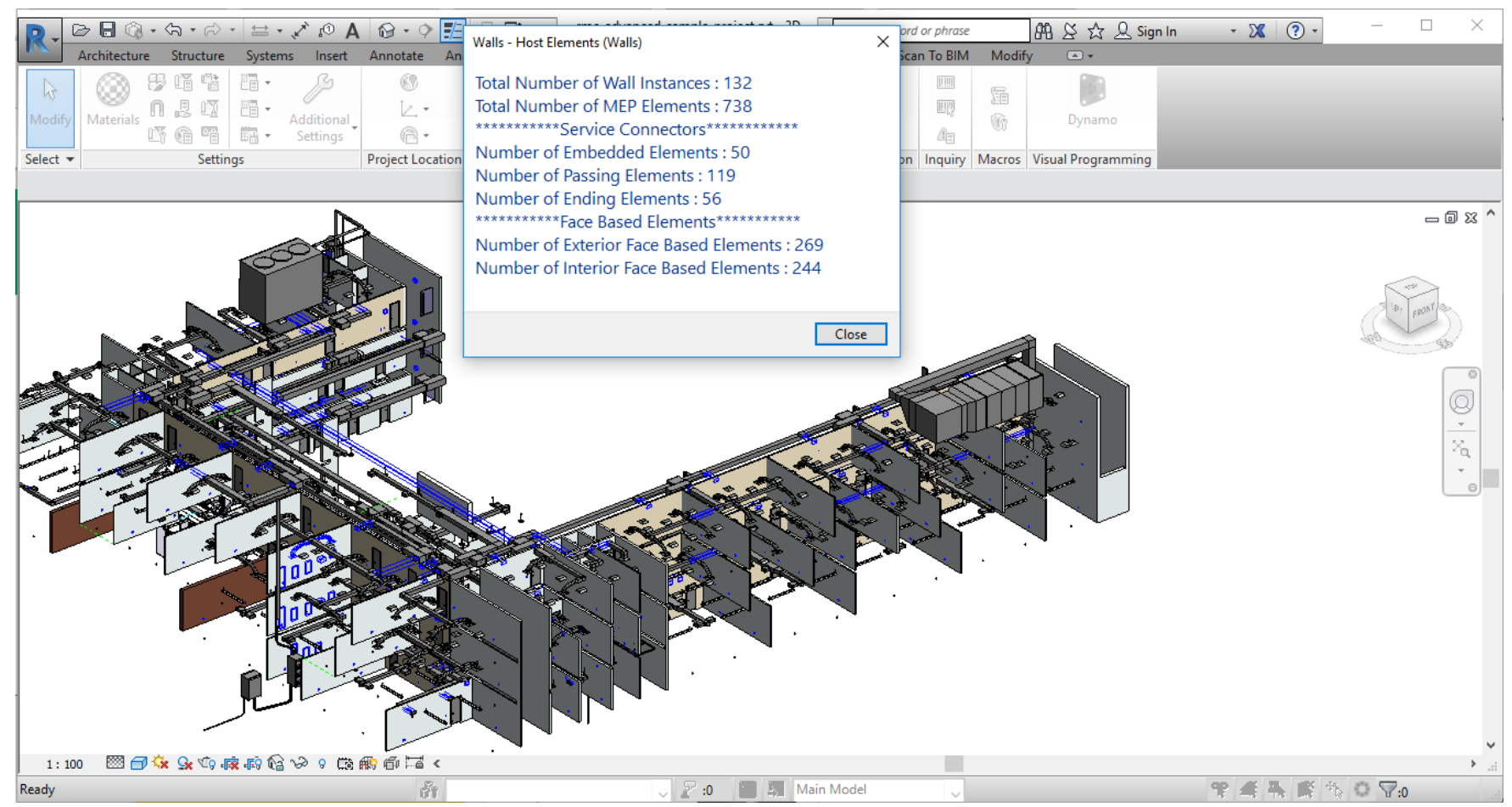

Figure 7. Visualization of the functionality output for wall objects as host elements.

Table 3 represents the exported output of nodes and edges. The right table is the nodes table representing the ID, Type, and Category of all elements, while the left table is the Edges table with each row representing an edge between a "host" and a "hosted" element. In addition, the label represents the relationship type. The nodes sample includes, besides the wall objects, several MEP elements. These elements include lighting devices such as "passive infrared $227 \mathrm{~V}$ ", electrical fixtures "standard elec", pipe curves "standard pipes", and electrical equipment "LP-3B".

\section{Conclusions}

Waste generated from demolition processes is considered a major challenge in the construction industry. The task of extracting the salvaged elements from the buildings to be demolished is deemed to be a complex and time-consuming process. Besides, when elements with high recovery potential are dismantled from the building, they might need to be stored for a long time until a demand arises for them. Therefore, the planning of deconstruction projects remains a crucial process to achieve a circular economy. Several efforts have been conducted to optimize the planning of demolition projects. Both qualitative and quantitative analysis do exist in the literature. However, the focus was either on strategic planning only or the operational one. The proposed research intended to integrate the efforts in the literature and in practice. It involves the creation of a multi-sided platform for linking the supply of salvaged elements with the demand. This platform was synchronized with the as-built BIM model for the building to optimize the deconstruction planning. The research was built on the exploitation of the BIM-centered process and functionalities. These functionalities were examined for conformity with lean principles by using an interaction matrix. The results showed the overall compatibility of BIM functionalities with lean principles. Moreover, a .NET plug-in was developed as a part of the BIM application to map the different physical and functional relationships between building elements. These relationships were then visualized using a semantic network. Finally, the process of plug-in applicability was demonstrated and analyzed on MEP systems to illustrates its practical features and to highlight its reliability. This research mapped the interaction between each lean principle against BIM functionalities one at a time. However, 
the lean-BIM interaction should be seen as a complex process where the interaction occurring between a lean principle and BIM functionality might intensify or attenuate the effect of other interactions. Future research can utilize system dynamics modeling to understand the non-linear behavior of the complex system covering lean and BIM integration in the deconstruction process.

Author Contributions: Conceptualization, M.M.; Methodology, M.M. and A.E.; Validation, A.E. Formal analysis, M.M. and A.E.; Investigation, M.M. and A.E.; Writing-original draft preparation, M.M. and A.E.; Writing—review and editing, M.M. and A.E.; Visualization, A.E.; Supervision, M.M.; Project administration, M.M. All authors have read and agreed to the published version of the manuscript.

Funding: This research has received no funds.

Institutional Review Board Statement: Not applicable.

Informed Consent Statement: Not applicable.

Data Availability Statement: The datasets used and/or analyzed during the current study are available from the corresponding author on reasonable request.

Conflicts of Interest: The authors declare no conflict of interest.

\section{References}

1. Wang, J.; Yuan, H.; Kang, X.; Lu, W. Critical success factors for on-site sorting of construction waste: A China study. Resour. Conserv. Recycl. 2010, 54, 931-936. [CrossRef]

2. European Commission. European Commission-Environment-Construction and Demolition Waste (CDW). Available online: http:/ / ec.europa.eu/environment/waste/construction_demolition.htm (accessed on 18 April 2018).

3. Hosseini, M.; Chileshe, N.; Rameezdeen, R.; Lehmann, S. Reverse Logistics for the Construction Industry: Lessons from the Manufacturing Context; Scientific and Academic Publishing: Rosemead, CA, USA, 2014.

4. Durmisevic, E.; Yeang, K. Designing for disassembly (DfD). Archit. Des. 2009, 79, 134-137. [CrossRef]

5. Durmisevic, S.; Durmisevic, E. A Knowledge Model for Assessment of Transformation Capacity with Respect to Spatial Flexibility; The British University in Dubai (BUid): Dubai, United Arab Emirates, 2006; pp. 762-770.

6. Kuehlen, A.; Thompson, N.; Schultmann, F.; Nakajima, S.; Russell, M. Barriers for deconstruction and reuse/recycling of construction materials in Germany. In Barriers for Deconstruction and Reuse/Recycling of Construction Materials; CIB Publications, CIB General Secretariat Publisher: Rotterdam, The Netherlands, 2014; pp. 38-52.

7. Hübner, F.; Volk, R.; Kühlen, A.; Schultmann, F. Review of project planning methods for deconstruction projects of buildings. Built Environ. Proj. Asset Manag. 2017, 7, 212-226. [CrossRef]

8. Schultmann, F.; Sunke, N. Organisation of reverse logistics tasks in the construction industry. In Challenges for the New Millennium, Proceedings of the Portugal SB07: Sustainable Construction, Materials and Practices, Amsterdam, The Netherlands; Braganca, L., Pinheiro, M., Jalali, S., Eds.; IOS Press: Amsterdam, The Netherlands, 2007; pp. 577-584.

9. Hosseini, M.; Chileshe, N.; Rameezdeen, R.; Lehmann, S. Sensitizing the Concept of Reverse Logistics (RL) for Construction Context. In Proceedings of the International Conference on Civil Engineering Architecture \& Urban Sustainable Development, Tabriz, Iran, 18-19 December 2013.

10. Schultmann, F.; Rentz, O. Environment-oriented project scheduling for the dismantling of buildings. OR-Spektrum 2001, 23, 51-78. [CrossRef]

11. Thomsen, A.; Schultmann, F.; Kohler, N. Deconstruction, Demolition and Destruction; Taylor \& Francis: Boca Raton, FL, USA, 2011.

12. Chini, A.R.; Bruening, S. Deconstruction and Materials Reuse: An International Overview (Final Report of Task Group 39 on Deconstruction); CIB: Rotterdam, The Netherlands, 2005.

13. Fleischmann, M. Quantitative Models for Reverse Logistics; Springer Science \& Business Media: Berlin/Heidelberg, Germany, 2001; Volume 501.

14. Schultmann, F; Sunke, N. Closed-loop oriented project management in construction: An approach for sustainable construction management. In Proceedings of the Conference Rethinking Sustainable Construction 2006, Sarasota, FL, USA, 19-22 September 2006.

15. Abdullah, A.; Anumba, C.J.; Durmisevic, E. Decision tools for demolition techniques selection. In Proceedings of the 11th Rinker International Conference on Deconstruction and Materials Reuse, Gainesville, FL, USA, 7-10 May 2003; pp. 55-72.

16. Abdullah, A.; Anumba, C.J. Decision model for the selection of demolition techniques. In Advances in Building Technology; Elsevier: Amsterdam, The Netherlands, 2002; pp. 1671-1679.

17. Anumba, C.J.; Abdullah, A.; Ruikar, K. An integrated system for demolition techniques selection. Archit. Eng. Des. Manag. 2008, 4, 130-148. [CrossRef]

18. Anumba, C.; Abdullah, A.; Fesseha, T. Selection of demolition techniques: A case study of the Warren Farm Bridge. Struct. Survey 2003, 21, 36-48. [CrossRef] 
19. Liu, C.; Lyle, B.; Langston, C. Estimating demolition costs for single residential buildings. Constr. Econ. Build. 2003, 3, 33-42. [CrossRef]

20. Kourmpanis, B.; Papadopoulos, A.; Moustakas, K.; Kourmoussis, F.; Stylianou, M.; Loizidou, M. An integrated approach for the management of demolition waste in Cyprus. Waste Manag. Res. 2008, 26, 573-581. [CrossRef]

21. Schultmann, F.; Sunke, N. Energy-oriented deconstruction and recovery planning. Build. Res. Inf. 2007, 35, 602-615. [CrossRef]

22. Volk, R.; Hübner, F.; Schultmann, F. Robust multi-mode resource constrained project scheduling of building deconstruction under uncertainty. In Proceedings of the MISTA 2015 Proceedings, Prague, Czech Republic, 25-28 August 2015; pp. 638-644.

23. Sunke, N. Planning of Construction Projects: A Managerial Approach. Ph.D. Thesis, Universität Siegen, Siegen, Germany, 2008.

24. NBIS Building Information Modelling. Available online: https://www.nationalbimstandard.org/ (accessed on 11 January 2018).

25. Akhoundan, M.R.; Khademi, K.; Bahmanoo, S.; Wakil, K.; Mohamad, E.T.; Khorami, M. Practical use of computational building information modeling in repairing and maintenance of hospital building-case study. Smart Struct. Syst. 2018, 22, 575-586.

26. Marzouk, M.M.; Hisham, M.; Al-Gahtani, K. Applications of bridge information modeling in bridges life cycle. Smart Struct. Syst. 2014, 13, 407-418. [CrossRef]

27. Krygiel, E.; Nies, B. Green BIM: Successful Sustainable Design with Building Information Modeling; John Wiley \& Sons: Hoboken, NJ, USA, 2008.

28. Akinade, O.O.; Oyedele, L.O.; Bilal, M.; Ajayi, S.O.; Owolabi, H.A.; Alaka, H.A.; Bello, S.A. Waste minimisation through deconstruction: A BIM based Deconstructability Assessment Score (BIM-DAS). Resour. Conserv. Recycl. 2015, 105, 167-176. [CrossRef]

29. Akanbi, L.A.; Oyedele, L.O.; Akinade, O.O.; Ajayi, A.O.; Delgado, M.D.; Bilal, M.; Bello, S.A. Salvaging building materials in a circular economy: A BIM-based whole-life performance estimator. Resour. Conserv. Recycl. 2018, 129, 175-186. [CrossRef]

30. Bilal, M.; Oyedele, L.O.; Qadir, J.; Munir, K.; Akinade, O.O.; Ajayi, S.O.; Alaka, H.A.; Owolabi, H.A. Analysis of critical features and evaluation of BIM software: Towards a plug-in for construction waste minimization using big data. Int. J. Sustain. Build. Technol. Urban Dev. 2015, 6, 211-228. [CrossRef]

31. Akbarnezhad, A.; Ong, K.C.G.; Chandra, L.R. Economic and environmental assessment of deconstruction strategies using building information modeling. Autom. Constr. 2014, 37, 131-144. [CrossRef]

32. Cheng, J.C.P.; Ma, L.Y.H. A BIM-based system for demolition and renovation waste estimation and planning. Waste Manag. 2013, 33, 1539-1551. [CrossRef]

33. Cheng, J.C.P.; Kumar, S. A BIM-based framework for material logistics planning. In Proceedings of the 23rd Annual Conference of the International Group for Lean Construction, Perth, Australia, 29-31 July 2015; pp. 33-42.

34. Toghroli, A.; Shariati, M.; Sajedi, F.; Ibrahim, Z.; Koting, S.; Mohamad, E.T.; Khorami, M. A review on pavement porous concrete using recycled waste materials. Smart Struct. Syst 2018, 22, 433-440.

35. Shariati, M.; Heyrati, A.; Zandi, Y.; Laka, H.; Toghroli, A.; Kianmehr, P.; Safa, M.; Salih, M.N.A.; Poi-Ngian, S. Application of waste tire rubber aggregate in porous concrete. Smart Struct. Syst. 2019, 24, 553-566.

36. Dinh-Cong, D.; Keykhosravi, M.H.; Alyousef, R.; Salih, M.N.A.; Nguyen, H.; Alabduljabbar, H.; Alaskar, A.; Alrshoudi, F.; Poi-Ngian, S. The effect of wollastonite powder with pozzolan micro silica in conventional concrete containing recycled aggregate. Smart Struct. Syst. 2019, 24, 541-552.

37. Sacks, R.; Koskela, L.; Dave, B.A.; Owen, R. Interaction of lean and building information modeling in construction. J. Constr. Eng. Manag. 2010, 136, 968-980. [CrossRef]

38. Dave, B.; Boddy, S.; Koskela, L. Visilean: Designing a Production management system with lean and BIM. In Proceedings of the 19th Annual Conference of the International Group for Lean Construction, Lima, Peru, 13-15 July 2011; pp. 477-487.

39. Bhatla, A.; Leite, F. Integration framework of bim with the last planner systemtm. In Proceedings of the IGLC 2012-20th Conference of the International Group for Lean Construction, San Diego, CA, USA, 17-22 July 2012.

40. Tillmann, P.; Viana, D.; Sargent, Z.; Tommelein, I.; Formoso, C. BIM and Lean in the Design production Interface of ETO Components in Complex Projects. In Proceedings of the 23rd Annual Conference of the International Group for Lean Construction, Perth, Australia, 29-31 July 2015; pp. 331-340.

41. Tillmann, P.; Sargent, Z. Last planner \& BIM integration: Lessons from a continuous improvement effort. In Proceedings of the 24th Annual Conference of the International Group for Lean Construction, Boston, MA, USA, 20-22 July 2016.

42. Eckblad, S.; Ashcraft, H.; Audsley, P.; Blieman, D.; Bedrick, J.; Brewis, C.; Hartung, R.J.; Onuma, K.; Rubel, Z.; Stephens, N.D. Integrated Project Delivery—A Working Definition; AIA California Council: Sacramento, CA, USA, 2007; p. 25.

43. Mom, M.; Hsieh, S.-H. Toward Performance Assessment of BIM Technology Implementation; Publishing House ASV Moscow: Moscow, Russia, 2012; pp. 27-29.

44. Khanzode, A.; Fischer, M.; Reed, D.; Ballard, G. A Guide to Applying the Principles of Virtual Design E Construction (VDC) to the Lean Project Delivery Process; CIFE, Stanford University: Palo Alto, CA, USA, 2006.

45. Gilligan, B.; Kunz, J. VDC Use in 2007: Significant Value, Dramatic Growth, and Apparent Business Opportunity; TR171; Center for Integrated Facility Engineering: Stanford, CA, USA, 2007; p. 36.

46. Oskouie, P.; Gerber, D.J.; Alves, T.; Becerik-Gerber, B. Extending the interaction of building information modeling and lean construction. In Proceedings of the IGLC 2012-20th Conference of the International Group for Lean Construction, The International Group for Lean Construction, San Diego, CA, USA, 17-22 July 2012; pp. 111-120. 
47. Cheng, J.C.P.; Won, J.; Das, M. Construction and demolition waste management using BIM technology. In Proceedings of the 23rd Ann. Conference of the International Group for Lean Construction, Perth, Australia, 29-31 July 2015; pp. 381-390.

48. Akinade, O.O.; Oyedele, L.O.; Omoteso, K.; Ajayi, S.O.; Bilal, M.; Owolabi, H.A.; Alaka, H.A.; Ayris, L.; Looney, J.H. BIM-based deconstruction tool: Towards essential functionalities. Int. J. Sustain. Built Environ. 2017, 6, 260-271.

49. Ge, X.J.; Livesey, P.; Wang, J.; Huang, S.; He, X.; Zhang, C. Deconstruction waste management through 3d reconstruction and bim: A case study. Vis. Eng. 2017, 5, 1-15. [CrossRef]

50. Marzouk, M.; Elmaraghy, A.; Voordijk, H. Lean Deconstruction Approach for Buildings Demolition Processes using BIM. Lean Constr. J. 2019, 147-173.

51. Elmaraghy, A.; Voordijk, H.; Marzouk, M. An exploration of BIM and lean interaction in optimizing demolition projects. In Proceedings of the 26th Annual Conference of the International Group for Lean Construction: Evolving Lean Construction towards Mature Production Management across Cultures and Frontiers, International Group for Lean Construction, Chennai, India, 16-22 July 2018; pp. 16-22.

52. Revit, A. Dynamo-Community-Driven Open Source Graphical Programming for Design. Available online: http://dynamobim. org/ (accessed on 16 December 2017).

53. Revit, A. The Dynamo Primer. Available online: http:/ / dynamoprimer.com/en/ (accessed on 16 December 2017).

54. Khanzode, A. An Integrated, Virtual Design and Construction and Lean (IVL) Method for Coordination of MEP; Unpublished Technical Report; Center for Integrated Facility Engineering: Stanford, CA, USA, 2010; Volume 187.

55. Revit, A. Revit Sample Project Files. Available online: https://knowledge.autodesk.com/support/revit-products/gettingstarted/caas/CloudHelp/cloudhelp/2016/ENU / Revit-GetStarted / files / GUID-61EF2F22-3A1F-4317-B925-1E85F138BE88htm.html (accessed on 12 February 2018). 